\title{
La evolución constitucional del derecho a la libertad de creación artística
}

The constitutional evolution of law to the freedom of artistic creation

\author{
Manuel A. BRAVO VELÁSQUEZ ${ }^{1}$ \\ Universidad de Chile \\ mbravo.velasquez@gmail.com
}

\section{Resumen}

En este artículo pretendemos realizar una revisión respecto a la trayectoria constitucional que ha tenido el denominado "Derecho a la libertad de creación artística", en la perspectiva que será éste prontamente debatido con ocasión del proceso constituyente. Este análisis comenzará con la que ha sido la tradición constitucional chilena, y cómo por el transcurso de las décadas, la legislación ha realizado su labor en cuanto a comenzar a pulir, desgranar y delimitar este derecho de una forma más perfectible y exacta, en consonancia al mayor desarrollo del catálogo de derechos en el siglo XX y asimismo de las nuevas formas y expresiones del arte en general. Aquí, lo que interesa es el medio de expresión, el canal, soporte, registro, material, acto u acción artística, circunscrita a su desenvolvimiento mediato o inmediato de carácter original, en la perspectiva que como toda expresión susceptible de vanguardia y desarrollo, presenta una continua e irrefrenable evolución, siempre adelanta a la vetusta maquinaria jurídica, la cual, en muchas ocasiones, como se verá, más entorpece o confunde el desenvolvimiento de la voluble esencia de este derecho de rango constitucional.

Palabras claves: Derecho; Constitución; Libertad; Creación artística; Garantías Constitucionales; Derecho de Autor. 1 Egresado de Derecho de la Facultad de Derecho de la Universidad de Chile. Diplomado en Historia del
Arte de la Pontificia Universidad Católica de Valparaíso. 


\begin{abstract}
In this article we pretend to do a revision according to the constitutional career path that has had the so called "Right to Freedom of Artistic Creation", due to the fact that this topic will be soon discussed during the Constituent Process. This analysis will start with the one that has been the Chilean Constituent Tradition and how during the decades, the law has done its job when speaking of to start improving, breaking down and defining this right in a more perfect and exact way, and according to a bigger catalogue of rights in the XX century, and also the new art's shapes and expressions in general. Here, what matters is the media, the channel, the support, recordings, materials, acts and/or artistic actions, limited by its unique immediate or mediate performance, in the perspective of every susceptible cutting-edge and development expression shows a continued and unstoppable evolution, always ahead of the ancient legal machinery, which, in many occasions, as it will be shown later, hinder or make confusing the development of the unstable essence of this constitutional range right.
\end{abstract}

Key Words: Law; Constitution; Freedom; Artistic Creation; Constitutional Guarantees; Copyright.

\title{
1. Introducción
}

Desde siempre las artes han estado presente en el desarrollo de la civilización humana; componente importantísimo y fundamental, han devenido desde las formas rupestres de dibujos simbólicos hasta otras que prescinden ya de su componente físico para ser realizados de manera abstracta; y ante ello, la dogmática constitucional se encuentra desacompasada, pues incluso en aquellas naciones más desarrolladas en el ámbito jurídico hispanoamericano no existe meridiana claridad sobre de qué se habla cuando se habla del derecho a la libertad de creación artística.

En este artículo pretendemos señalar de manera general la evolución de las artes dentro del ámbito normativo constitucional chileno; todo, con miras al actual proceso constituyente iniciado a partir de octubre del año 2020, y que posee como expectativa promulgar una nueva constitución a partir del año 2022. Es por esto que es pertinente realizar una breve síntesis histórica del papel de las artes y de sus creadores en las sucesivas constituciones chilenas, expresar una crítica a la normativa actualmente vigente, y formular contribuciones al debate constitucional actual, en la perspectiva de que la creación artística no solo ha evolucionado en sus formas de expresión durante el siglo XX y XXI, sino que también en sus soportes.

Ya la clásica distinción de las bellas artes ha quedado sobrepasada por la realidad, incorporándose nuevas como instalaciones artísticas, performance, body-art, land-art, grafitti, arte sonoro, arte virtual, arte urbano o videoarte, a la lista de 
expresiones dotadas de una dimensión estética y/o simbólica, representativas de la personalidad del autor, el cual también ha sufrido variaciones en la sociedad contemporánea, impulsándose la creación colectiva hasta niveles multitudinarios, y con ello, la cantidad de agentes partícipes de la actividad artística, como lo son agentes, productores, curadores o editores. Considérese además que la cultura ha sido ya reconocida como uno de los principales motores del desarrollo sostenible de las comunidades, los pueblos y las naciones hacia el futuro².

Junto a ello, es dable señalar que existe una tensión evidente que cruzará todo este análisis y que se relaciona con la dificultosa diferenciación entre el derecho a la libertad de expresión y el derecho a la libertad de creación artística; tema que desarrollaremos en detalle más adelante, pero que presentaremos en este espacio inicial con una primera distinción sobre el especial atributo que contiene el arte: su absoluta subjetividad:

El arte es a la vez algo más y algo menos: debe contener voluntad manifiesta de expresión, pero, de la misma forma que cualquier otra actuación humana, es, a su vez, una exposición de intenciones o de comportamientos. Puede ser un instrumento de información, pero con voluntad de conseguir una cosa diferente. Puede ser una forma de disfrute, gozo o placer, y también lo puede ser, contraria o complementariamente, de sensibilidad, pena y dolor. (...) El arte depende tanto del objeto como del sujeto que, de forma activa o pasiva, participa en los efectos de la obra artística (Martínez Dalmau, 2014: 36).

\section{Las artes y el derecho durante el período indiano}

Ciertamente, el sustrato identitario de las culturas precolombinas son herencia permanente en el ámbito artístico y cultural de América Latina; herencia que fue el resultado de un largo proceso de sincretismo entre la cultura occidental de componentes clásicos y grecolatinos traída por el Imperio Español y la cultura generada en este continente por diversos pueblos indígenas en la vastedad enorme del territorio. Este proceso no solo tiene la particularidad de desenvolverse a lo largo de más de tres siglos de dominación española; también posee la característica que desde los inicios del período indiano trajo consigo un intento de evangelización y educación sobre los pueblos dominados que no conoció parangón en la historia universal, en consonancia al impulso enciclopédico de la Ilustración (Stolley, 1996: 383), pues no solo se deseaba la formación de colonias con miras a exclusivos intereses comerciales o de control estratégico con una burocracia menor, como lo fue

\footnotetext{
2 Convención de las Naciones Unidas sobre la Promoción y Protección de la Diversidad de Expresiones
} Culturales. 2005. Ratificada por el Chile el 27 de junio de 2007. 
el caso de los modelos de colonización inglés y holandés (Ferguson, 2005: 96), sino que buscaba como fin último, la conformación de una nación gigantesca que respondiera directamente a la figura del emperador con autonomía respecto al resto de las cortes regionales (Bravo Lira, 2017: 62), trasladándose al Nuevo Mundo todos los aspectos de la cultura española. De ahí entonces, surge la consideración de los indios como súbditos del rey, la proliferación de colegios y universidades, el recio control sobre el comercio marítimo entre ambos continentes y el establecimiento de fuertes, fortalezas, castillos y unidades militares asentadas de manera permanente. Esta "vocación" imperialista, cimentada durante el siglo XVII marca su principal diferencia con el resto de las naciones europeas precisamente en el ámbito educativo (Encina, 1956: 9).

Sin embargo, esta pretensión no desembocó en la formación de un fuerte y autónomo espacio cultural, pues fue obstaculizado por las limitaciones de la época, en donde la diferencia de tratamiento entre peninsulares y criollos, y aún más entre peninsulares y mestizos impidió la asimilación plena de la cultura española. En consecuencia, el apogeo que significó, por ejemplo, el siglo de Oro español, no se tradujo en la irradiación del mismo hacia los territorios americanos. Lo que conllevó a que, a la declinación de éste, la situación de las artes dentro de la América Hispana continuara invariable, es decir, sumida en la formación de un desarrollo cultural y educativo de carácter primitivo y larvario (Encina, 1956: 21). Aunque nada implica que no existieran manifestaciones artísticas de sumo grado: las obras de Inca Garcilaso de la Vega o Sor Juana Inés de la Cruz; las escuelas pictóricas de Quito y Lima, convertidas en verdaderas tradiciones coloniales; la conformación de un cuerpo de artesanos especialistas en orfebrería y platería reconocida a nivel planetario; el mantenimiento y perfeccionamiento de la rica tradición textil indígena; y por sobre todo, el aprendizaje y consolidación del idioma español en los territorios conquistados son ejemplo de ello, generándose una subcultura propia:

En América Virreynal nos enfrentamos a una complicadísima situación pluridimensional. Por un lado, la literatura -fueren crónicas, cartas, poemas, diarios, etc.- se escriben en virtud de las modalidades europeas. El contacto con la nueva realidad introduce elementos distintos que van a crear una literatura diferente. Entonces, tanto autores como obras son bivalentes, en distinto grado y modo. A la vez, todo ese conjunto muy diverso se integra dentro de las literaturas hispánicas, tanto románticas como las de Occidente. ¿Es posible concebir esta supra-realidad literaria y cultural multifacética como una nueva entidad? Sólo la relación con España suele originar casos confusos, que mueve a ver a los mismos autores desde una perspectiva dual: peninsular y americana (Anadón, 2015: 411). 
Y si bien no se conformó un cuerpo social mayoritario sensible a las artes o al menos inclinados a ella; sí se conformó dentro de la realidad indiana un cuerpo social destinado preferentemente a las labores artísticas: el artesanado. Grupo sistémico, pues tendió a la organización a través de asociaciones de gremios, de escultores, orfebres, pintores, doradores o grabadores, los que tenía como principales clientes a los terratenientes y a la Iglesia, siendo su característica principal la confección de diversos productos de uso cotidiano (Prieto, 2013: 165).

En el caso chileno, cabe señalar que ésta era la más alejada de las provincias hispanoamericanas y que además, poseía como rasgo esencial la conformación de una sociedad altamente militarizada debido a las constantes fricciones bélicas acaecidas en la frontera de Arauco y el establecimiento de un ejército permanente en este territorio (Concha, 2016: 358); lo que en su momento, generó que todo el esfuerzo educativo residiera desde un inicio solo en las congregaciones eclesiásticas y que el desarrollo de la intelectualidad criolla fuera tardío y extremadamente escalonado. A mediados del siglo XVIII se funda la primera universidad (Real de San Felipe), la que dicta en sus inicios las cátedras de teología y derecho con énfasis en aspectos religiosos (Subercaseaux, 2000: 9), y es recién a fines del mismo siglo en que se vislumbra la conformación de una red educativa de mediano alcance. Evolución que fue obstruida por la expulsión de los jesuitas decretada por el monarca español Carlos III y que devino en un clima intelectual ciertamente escaso, pequeño y desestimulante para los fines de la Ilustración que alcanzaba su apogeo en el continente europeo.

Pues en Europa el escenario era diametralmente distinto. Todo era efervescencia intelectual en el viejo continente: Newton, Smith, Montesquieu, Rousseau, Locke, Hume, Mill, Leibniz, Descartes, Spinoza y Grocio, entre otros, contribuyeron fuertemente a la idea de que era la libre manifestación del pensamiento y la libertad de expresión "la más urgente de las necesidades humanas" (Dunn, 2014: 111), lo que fue suministro sustancial para la estructuración de un cuerpo de ideas de carácter ilustrado y moderno, sobre el cual la sociedad de la época debatía con frenesí.

Sumado a esto, el ambiente activo y dinámico creado por Revolución Industrial, y la institución de una clara tradición constitucionalista nacida al alero de la Carta Magna de 1215 y del Bill of Rights de 1689 marcan el punto inicial de consagración de los derechos del hombre en la forma de garantías individuales, al menos de manera tácita. Conjuntamente, se puede señalar que, con la Independencia de los Estados Unidos de América en 1776 comienza un período revolucionario que promueve una concepción universal de los derechos del ser humano a través de un proceso de codificación jurídica (Figueroa, 1967: 34), y que, junto al nacimiento del presidencialismo y la conformación de un gobierno de rasgos democráticos y representativos, irá adquiriendo una operativización concreta mediante textos legales, y una continua renovación en manos de su fuerte protagonismo en el debate público durante el devenir del siglo. 
Proceso que alcanza su punto irreversible con la Revolución Francesa en 1789, iniciándose una serie de cambios políticos, económicos y sociales que confluyen en un nuevo entendimiento de los alcances de la persona humana, perdurando sus efectos hasta la actualidad. Traduciéndose en un avance respecto al pre-constitucionalismo medieval, que derivaría en una declaración de derechos fundamentales con vocación universal de carácter inalienable, absoluto y perpetuo (Pereira, 1998: 365). Consignándose, en una primera fase, aquellos denominados como derechos de "primera generación”, o "civiles y políticos", entre los cuales se cuentan: el derecho a la vida, a la integridad física, la igualdad ante la ley, la seguridad personal, la libertad de expresión y el derecho de propiedad, entre otros. Éstos presentan como rasgo fundamental la exigencia al Estado de un principio de no-intervención, tanto en la persona como en sus bienes, o bien, lo que se ha entendido como derechos y libertades en sentido negativo (Pereira, 1998: 395). Algunos juristas llaman a estos derechos también como derechos de defensa, pues se consideran originarios del estado liberal y son representativos de la separación entre la Sociedad y el Estado, al ser objetivo primordial la preservación de la intervención estatal, en situaciones de especial importancia para la persona humana (Escobar, 1998: 141).

Revolución, o cambio de paradigma que alcanza a la dimensión artística del ser humano pues se le reconoce como elemento intrínseco de la persona y, por tanto, extensión inherente de su facultad y ejercicio de creación, de su propia personalidad, de su capacidad de inventiva e imaginación y, por consiguiente, de su inteligencia:

El romanticismo postrevolucionario refleja un sentido nuevo del mundo y de la vida y hace madurar sobre todo una nueva interpretación de la idea de libertad artística. Esta libertad ya no es el privilegio de un genio, sino el derecho innato de todo artista y de todo individuo con capacidad. El prerromanticismo autorizaba solo al genio a apartarse de las reglas; el romanticismo niega el valor de toda regla artística objetiva. Toda expresión individual es única, insustituible, y tiene sus propias leyes y su propia tabla de valores en sí; esta visión es la gran conquista de la Revolución para el arte (Hauser, 2012: 167).

Y en la consideración de que tanto la libertad como la igualdad son atributos esenciales de la persona humana, es que se obtiene la razón fundamental sobre la cual se extiende la vocación universal relativa a la aplicación de estos derechos y su intencionalidad normativa mediante la ley, siendo la constitución belga de 1831 la primera en establecer dentro de sus articulados un capítulo sobre derechos fundamentales (Pereira, 1998: 393). Y son estos primeros derechos, los que le entregan a la figura del artista, y por extensión, al arte en general, la atribución de convertirse en un derecho de rango constitucional susceptible de ser protegido por el derecho, al menos en el ámbito europeo. 


\section{Las artes y el derecho durante el período decimonónico}

En Hispanoamérica, en cambio, el panorama era diferente y es recién con ocasión del secuestro del rey de España, Fernando VII, que se inician los procesos independentistas tanto en la forma, a través de la creación de ejércitos independientes, como en el fondo, con la declaración de actos de libre autodeterminación y soberanía. Chile inicia tal proceso un 18 de septiembre de 1810, abriéndose el período de la Independencia. Empero, el ambiente intelectual de la época continuaba constreñido a las consideraciones sociales del período indiano (Subercaseaux, 2000: 15), manteniéndose entonces la concepción del artista dentro del precario artesanado chileno:

En su extremo superior, el artesanado se confundía con las capas más bajas de la elite, especialmente aquellos artesanos que se especializaban en bienes de lujo, como paleteros y plateros. Al otro extremo, artesanos pobres con bajos niveles de calificación, como zapateros y hojalateros, ganaban un sueldo ínfimo y no se diferenciaban mayormente de la plebe urbana. La palabra artesano también se usaba para referirse a los artistas, incluyendo pintores, escultores, compositores y músicos (Daistman, 1998: 89).

Artesanos que, para los períodos iniciales de la república, alcanzaban a conformar el cincuenta por ciento de la población urbana (Daistman, 1998: 90). En el aspecto de la retórica política, desde sus inicios se tuvo en consideración la figura tanto del artista como del artesano, pero ello no se tradujo en una específica mención dentro del articulado constitucional de la época. En el caso del Reglamento Constitucional Provisorio de 1812 promulgado durante el gobierno de José Miguel Carrera, la única garantía establecida dentro del ámbito que ya hemos señalado como el relativo a las artes es la libertad de expresión mediante la prensa. Señala éste:

Art. 23. La imprenta gozará de una libertad legal; y para que ésta no degenere en licencia nociva a la religión, costumbres y honor de los ciudadanos y del país, se prescribirán reglas por el Gobierno y Senado.

Posteriormente, transcurrido el período conocido como la Patria Vieja, el general Bernardo O'Higgins lidera un régimen de carácter autoritario que fue muy resistido en esos años, principalmente por su posición contra la rancia aristocracia criolla y su empeño personal por solventar la expedición libertadora del Perú, la que vació las arcas hacendarias chilenas y empobreció a la economía nacional. Este gobierno fundacional tuvo su dimensión constitucional al promulgarse la Constitución de 1822, la que realiza un tratamiento más detallado de las libertades e igualdades 
públicas, y en el caso de las artes, no sólo reconoce la existencia de las mismas es su preámbulo, sino que además expresa lo que sigue:

\section{Constitución Política del Estado de Chile de 1822:}

Art. 223. Sobre la libre manifestación de los pensamientos no se darán leyes por ahora; pero queden prohibidas la calumnia, las injurias y las excitaciones a los crímenes.

Art. 225. Es libre la circulación de impresos en cualquiera idioma; pero no podrán introducirse obras obscenas, inmorales e incendiarias.

Esta manifestación de pensamientos es indicativa del nuevo grado del que gozan los productos de la creación humana gracias a la Ilustración. Sin embargo, el Director Supremo abdica en la antesala de un pronunciamiento cívico-militar en su contra y decide el autoexilio hacia el Perú (Razuváev, 1989: 299). Asimismo, se realizan nuevas elecciones y es elegido el General Ramón Freire, férreo liberal, quien rápidamente ordena la confección de una nueva constitución, la cual, consciente de su carácter refundacional, más que destacar determinadas garantías constitucionales, en el caso específico de las artes les asigna un rol secundario, refiriéndose solo a aquellas que sean "útiles" a la naciente patria. A continuación, transcribimos el articulado:

\section{Constitución política del Estado de Chile, promulgada el 29 de diciembre de 1823:}

Art. 253. La sabiduría y los talentos literarios útiles a la Patria, serán premiados de este fondo, pero con la precisa y notoria calidad de probidad de costumbres y moralidad de opiniones.

Art. 255. Se encarga en la misma forma de la educación de los jóvenes en quienes se conozcan singulares talentos para las artes o ciencias.

Art. 262. La imprenta será libre, protegida y premiada en cuanto contribuya a formar la moral y buenas costumbres; al examen, y descubrimientos útiles de cuantos objetos pueden estar al alcance humano; a manifestar de un modo fundado las virtudes cívicas y defectos de los funcionarios en ejercicio; y a los placeres honestos $\mathrm{y}$ decorosos.

Cabe señalar que la siguiente Constitución, la denominada "federal" de 1826, no hace mención ni a la cultura y ni a las artes pues se trató básicamente de un cúmulo de leyes de carácter supra-normativo que fueron promulgadas a lo largo de ese año y que incidieron en la parte propiamente orgánica del Estado, con especial interés en su reglamentación territorial.

Posteriormente, José Joaquín de Mora lidera la redacción de una nueva carta fundamental bajo el gobierno liberal de Francisco Antonio Pinto en 1828. Y, tomando como antecedente la Constitución de Cádiz de 1812 - de la que fue parte en la Comisión 
Redactora-, reglamenta una mayor protección al ámbito privado de la vida humana, estableciendo que en ella no cabría ni fiscalización ni intervención estatal, potenciando en Chile, la faz negativa de las libertades:

\section{Constitución Política de la República de Chile promulgada el 8 de agosto de 1828:}

Ella establece las más formidables garantías contra los abusos de toda especie de autoridad; de todo exceso de poder. La libertad, la igualdad, la propiedad, la facultad de publicar vuestras opiniones, la de presentar vuestras reclamaciones y quejas a los diferentes órganos de la soberanía nacional, están al abrigo de todo ataque.

Art. 4. Nadie será perseguido ni molestado por sus opiniones privadas.

Art. 18. Todo hombre puede publicar por la imprenta sus pensamientos y opiniones. Los abusos cometidos por este medio, serán juzgados en virtud de una ley particular y calificados por un tribunal de jurados.

Las fricciones entre liberales y conservadores se acrecientan y la confrontación entorna ribetes bélicos al momento de declararse como viciada la elevación del vicepresidente Joaquín Vicuña (reemplazante de Pinto, quien renuncia); iniciándose entonces la guerra civil de 1829. Cabe destacar que el liberalismo de estos años poco tiene que ver con el que se consolidó después, durante los quinquenios liberales de mediados y finales de siglo. Aún no se vivía aquella ruptura ideológica que significaron las revoluciones liberales de 1851 y 1859 en Chile, y las de 1848 en Europa. Empero, lineamientos base se encontraban establecidos, y tendrían la vigencia de un siglo:

Estas aspiraciones son en el plano jurídico la soberanía del individuo y libertad como eje del sistema (libertad de imprenta, de culto, de prensa, de industria, electoral y de creación); en el ámbito político la forma republicana de gobierno y la separación e independencia de los poderes del Estado; en la historiografía de una nación que se inscribe en la ley del progreso y que se constituye como negación del pasado colonial; en las letras el afán de una literatura que exprese a la sociedad de la época y que emancipe a los espíritus de los valores del pasado; en el plano institucional, la separación entre la Iglesia y el Estado; en la educación, el predominio del laicismo racionalista; y en la vida social y en las costumbres: el afrancesamiento y la apropiación constante de modelos europeos (Subercaseaux, 2000: 45).

El triunfo, luego de la batalla de Lircay, queda en manos de los conservadores, sumergiéndose el país en un largo período conservador de más de treinta años. Es redactada una nueva carta fundamental de la mano de Mariano Egaña, la cual establecería un inflexible presidencialismo, un inamovible clericalismo y la 
conformación de un Estado-Nación de rasgos autoritarios que continuaría estable por más de nueve décadas. Era de esperar entonces que aquella Carta Magna no se refiriera en demasía a los derechos fundamentales (o, en el vocabulario de la época, "garantías constitucionales"), y en ello, su normativa es breve y concisa, pues, recordemos, buscaba ser la antítesis de la Constitución anteriormente promulgada. Sin embargo, es destacable el hecho que dentro de la nueva normativa se estableciera por primera vez la noción de autor, y conjuntamente el reconocimiento de su facultad de producción, ocasionando, en consecuencia, la figura del inventor, no habiendo sido ellas antes referidas; y eventualmente estableciendo una protección adicional al ejercicio de estos actos, al vincularlos no solo a la expresión (como había sido la inclinación general de la normativa constitucional hasta ese entonces), sino que también al derecho de propiedad:

\section{Constitución de la República de Chile de 1833}

Art. 12. La Constitución asegura a todos los habitantes de la República: 70 La libertad de publicar sus opiniones por la imprenta, sin censura previa, i el derecho de no poder ser condenado por el abuso de esta libertad, sino en virtud de un juicio en que se califique previamente el abuso por jurados, i se siga i sentencie la causa con arreglo a la lei.

Art. 151. Ninguna clase de trabajo o industria puede ser prohibida, a menos que se oponga a las buenas costumbres, a la seguridad o a la salubridad pública, o que lo esija el interés nacional, i una lei lo declare así.

Art. 152. Todo autor o inventor tendrá la propiedad esclusiva de su descubrimiento, o producción por el tiempo que le concediere la lei; i si ésta exijiere su publicación, se dará al inventor la indemnización competente.

Esta vinculación entre la figura del autor y la del derecho de propiedad, se estrecharía no solo con ocasión de la Ley de Propiedad Literaria y Artística de 1834, que establecía la protección de los derechos de autor por cinco años desde el fallecimiento del mismo a nivel nacional, a la que se sumó posteriormente la Ley de Privilegios Industriales de 1840 (Infante, 2019: 259), sino que aún más a causa de la promulgación del Código Civil de Andrés Bello, indicando éste que sobre los bienes incorporales recae una: "especie de propiedad" (Artículo 583). Vinculación que se ve reforzada en el artículo siguiente: "Las producciones del talento o del ingenio son una propiedad de sus autores. Esta especie de propiedad se regirá por leyes especiales" (Artículo 584).

Unidos, autor, creación y propiedad se vuelven un todo indisoluble. Cabe detenerse un poco en esta tríada, pues pensamos que esta vinculación tan estrecha con el derecho de propiedad es una de las causas del exacerbado tratamiento jurídico 
civil que se realiza en torno a las artes y el patrimonio, tratamiento vigente hasta el día de hoy, pues son escasas las ocasiones en que la obra artística de determinado autor forma parte del patrimonio cultural común de la nación sin que sea por consecuencia del tiempo. Asimismo, el tratamiento constitucional a las artes no tuvo avance en los siguientes cien años, precisamente a causa de esta visión disruptiva de la propiedad, que olvidaba el patrimonio común y veneraba la división del mundo entre las cosas propias y ajenas:

Fruto de dicha interpretación, habrá un principio que recorrerá -y recorre hoy- el Código Civil de Andrés Bello: el principio de la libre circulación de los bienes, el mismo que aborrece las sociedades, los bienes comunes, que las desata a voluntad a fin de devolver sobre las cosas un total dominio humano. Esta "circulación" hace pensar en cosas vagando sin designio ni órbita por el universo. Es un desorden universal de las cosas desatadas, cuya única gravitación universal es la propiedad pública y privada. En esta fuerza de atracción descansan las mínimas prohibiciones del derecho privado, las cuales dicen relación con el derecho universal que se tiene respecto de todas las otras personas (derechos reales) y los derechos que se tienen en relación a una o varias personas (derechos personales). Andrés Bello creía religiosamente en esta iuscosmología (Trujillo Silva, 2019: 128).

La figura del artista no es mencionada en el Código, no existe a través de sus ejemplos, y solo se hace mención al escritor con ocasión de los contratos para la confección de una obra material y el arrendamiento de servicios inmateriales en el artículo 2.007. Esta inclinación por observar al artista como un propietario más, marcó la diferencia con lo acaecido en el continente europeo, pues la vida cultural chilena se vio limitada en sus desenvolvimientos al observarse siempre como el campo de acción de la confluencia de intereses netamente individuales, en armonía con el escaso interés desarrollado por parte de los juristas chilenos y latinoamericanos en los estudios relativos a la formación del conocimiento (Cerda, 2016: 22). No así en el viejo continente, donde las ideas de patrimonio artístico, patrimonio cultural común, y el mismo papel del artista dentro del debate público nacional obtendrían una preponderancia relevante.

\section{La Constitución de 1925}

Para las artes en Chile, las décadas finales del siglo XIX marcaron un progresivo avance, no en su reconocimiento, pero sí en los alcances de su protección, pues fueron añadiéndose sucesivamente las libertades de opinión y enseñanza, las que ampliaron las aulas y salones sobre los cuales podía ejercitarse eventualmente una manifestación 
artística. Al mismo tiempo, el debate sobre la libertad de expresión alcanzaba ya no solo a la prensa, sino también a los diversos géneros literarios, al dibujo, la ilustración, y el cómic. La fundación de la Academia de Pintura (1891) y posteriormente de la Escuela de Bellas Artes, marca la institucionalización de la enseñanza del arte en Chile, y por primera vez, la explicitación de la divergencia entre artesanos y artistas, quedando para los primeros una denominación de raíz obrera, y para los segundos, una denominación de raíz burguesa. La estratificación social y económica de la cual hace gala actualmente la nación, también tenía en estos años su permanencia exasperante.

En tanto, Chile suscribe en 1910 el Convenio sobre la Propiedad de Obras Literarias en Buenos Aires, entregándole protección interamericana a los autores de obras artísticas al incluir en ellas también la danza, el dibujo, la escultura, la arquitectura o la música. Haciéndose parte de un modelo de protección de los derechos de autor de carácter continental, en contraposición al modelo europeo surgido posteriormente al Convenio de Berna de 1886. Modelos que en su momento generaron explícitas diferencias en el tratamiento de derechos de propiedad intelectual, en particular al período posterior a la segunda guerra mundial, pero que posteriormente fueron amilanándose al punto de asimilarse, en conjunto al avance del multilateralismo financiero y político potenciado en la década de los años noventa (Cerda, 2016: 41).

Ubicada dentro del período de entreguerras, esta Constitución cuenta con las influencias normativas foráneas que propugnan el establecimiento del Estado como un prestador $\mathrm{u}$ otorgador preferente de servicios. Dejando atrás el cariz de las libertades negativas del período pre-constitucional y constitucional clásico, comienzan a surgir los denominados derechos sociales (o de segunda y tercera generación) que más bien buscan una libertad del tipo positivo, el cual, determina una acción o prestación desde el Estado en la forma de un derecho público subjetivo que faculta al titular para exigir una determinada conducta de una autoridad pública, estableciéndose un deber jurídico (Pereira, 1998: 402). Y en el caso de la Constitución de 1925, se mostró una apertura al establecimiento de deberes del Estado, como ocurre con la salubridad pública y el bienestar higiénico del país (artículo 10. ํํ14); preponderancias, al tratarse de la "conveniente división de la propiedad y la constitución de la propiedad familiar" (Artículo 10. ํ14); y "atenciones preferentes" en la educación pública (Artículo 10. $\mathrm{N}^{\circ} 7$ ), sin establecer ninguna de estas elegantes inclinaciones hacia para la cultura, el quehacer artístico o el patrimonio natural o cultural de la nación:

\section{Constitución Política de la República de 1925:}

Capítulo III 
Artículo 10. La Constitución asegura a todos los habitantes de la República:

Número 3.- La libertad de emitir, sin censura previa, sus opiniones, de palabra o por escrito, por medio de la prensa o en cualquiera otra forma, sin perjuicio de responder de los delitos y abusos que se cometan en el ejercicio de esta libertad en la forma y casos determinados por la ley. Número 11.- La propiedad exclusiva de todo descubrimiento o producción, por el tiempo que concediere la ley. Si ésta exigiere su expropiación, se dará al autor o inventor la indemnización competente.

Destinándose entonces toda regulación posible de las artes al decreto ley sobre la propiedad intelectual promulgado durante el mismo año. Allí se profundizan las bases generales de registro y validez de la propiedad intelectual en el territorio chileno, y los derechos exclusivos para el autor, los denominados derechos morales, como lo son los derechos de integridad, edición y paternidad de la obra. Se amplían además los oficios artísticos en consonancia a la modernidad de la época y se extiende el período de protección de estos derechos de autor hacia el horizonte de los veinte años:

La propiedad literaria o intelectual está regida por el Decreto Ley №345, de 5 de mayo de 1925. Como establece su artículo $1^{\circ}$ ella se "constituye por su inscripción en el Registro que se llevará en la Biblioteca Nacional...y consiste en el derecho exclusivo de distribuir, vender o aprovechar con fin de lucro una obra de la inteligencia por medio de la imprenta, litografía, grabado, copia, molde, vaciado, fotografía, película cinematográfica, discos de gramófono, rollo para instrumento mecánico, ejecución, conferencia, recitación, representación, traducción, adaptación, exhibición radio telefónica o cualquier otro medio de reproducción, multiplicación o difusión". Los autores o a quienes pertenece la primera idea en una "producción científica, literaria o artística, tendrán durante su vida la propiedad intelectual sobre esa producción" (Andrade, 1963: 233).

Y fue precisamente en este período que el clima intelectual y artístico chileno alcanzó su cénit. Al fortalecimiento institucional que se originó con la creación de diversos organismos públicos encargados de velar por el patrimonio cultural, como la Dirección de Bibliotecas, Archivos y Museos (DIBAM) creada en 1929, la instauración de diversas categorías de Premios Nacionales, y a una ampliación de la red educativa primaria y secundaria, se sumó un estimulante entorno cultural propio de una nación elocuente, el que formó escuela a nivel mundial con Gabriela Mistral, Pablo Neruda, Roberto Matta, Violeta Parra, Vicente Huidobro, Marta Colvin y tantos más que no 
fueron objeto ni de la atención, ni de la promoción ni de la preponderancia del Estado, a pesar de que sea éste el principal heredero y receptor de su legado.

\section{La Constitución de 1980}

Tal como en el siglo anterior, la confrontación política toma ribetes macabros y provoca el golpe de Estado de septiembre de 1973. Las fuerzas armadas obtienen el poder e inician una intensa persecución que terminaría con la muerte, tortura, exilio y destierro de miles de personas, el cese del consolidado desarrollo cultural chileno y la sumersión a décadas de oscurantismo creativo. Gobierna una Junta Militar encabezada por el Ejército, la que traería consigo un ánimo refundacional que tomaría forma a partir de 1975 con la apropiación por parte del gobierno de un poder constituyente derivado, a través de la dictación de Actas Constitucionales y nueva Constitución (Cristi, 1993, 238), la que potenciaría la faz individual de la persona humana, recogiéndose una concepción neoliberal de los derechos, entregándosele preminencia al derecho de propiedad y a las libertades del tipo negativo, fortaleciendo también el resguardo, cuidado y protección de los grupos intermedios de la "sociedad civil" (Correa y Ruiz Tagle, 2010: 126).

Declarándose recesada la Constitución de 1925, el 11 de septiembre de 1976 se promulga el Decreto Ley $\mathrm{N}^{\circ} 1552$. En este Decreto Ley se amplía el articulado tanto de la libertad de expresión como el derecho de autor sobre las creaciones artísticas e intelectuales de cualquier especie, comprendiéndose la propiedad de las mismas en conformidad a la ley, en lo que sería un resultado directo de la discusión acaecida dentro del seno de la Comisión Ortúzar.

Compuesta por especialistas en derecho constitucional, tales como Alejandro Silva Bascuñán, Enrique Ovalle Quiroz, Juan de Dios Carmona, Raúl Bertelsen, Sergio Diez Urzúa y Luz Bulnes, en sus actas ha quedado registrado el que fue el debate suscitado entre los partidarios de prevalecer los derechos morales sobre los derechos patrimoniales en materia de propiedad intelectual; confrontación genuina que sería zanjada en favor de los derechos patrimoniales, al poder ser éstos armonizados de mejor manera en la nueva Carta Magna. Debate transcurrido entre sus sesiones № ${ }^{\circ} 197$ y $\mathrm{N}^{\circ} 201^{3}$ :

\section{DECRETO LEY 1552}

De los derechos y deberes constitucionales CAPITULO I

De los derechos constitucionales y sus garantías

ARTICULO $1^{\circ}$ Los hombres nacen libres e iguales en dignidad. Esta Acta Constitucional asegura a todas las personas:

\footnotetext{
${ }_{3}^{3}$ Biblioteca del Congreso Nacional. Historia de la Ley $\mathrm{N}^{\circ} 19.742$.
} 
17.- El derecho del autor sobre sus creaciones intelectuales y artísticas de cualquier especie, por el tiempo que señale la ley y que no será inferior al de la vida del titular. Este derecho comprende la propiedad de las obras y otros derechos, como la paternidad, la edición y la integridad de la obra, todo ello en conformidad a la ley.

El trabajo de la Comisión Ortúzar sería antecedente para la elaboración del Anteproyecto Constitucional de 1978, y que luego de la revisión del Consejo de Estado y de la Presidencia usurpadora, se convertiría en el Proyecto Constitucional de 1980. Siendo ratificado en un plebiscito sin cédula electoral y sin la participación de partidos políticos u organizaciones sociales. No obstante, el articulado no presentaría mayores variaciones, salvo en lo señalado para el derecho a la educación, en donde se dejó de manera manifiesta la correspondencia al Estado en el fomento y la estimulación de la creación artística nacional:

\section{Constitución Política de la República de 1980:}

Artículo 19.- La Constitución asegura a todas las personas:

10 -. El derecho a la educación.

La educación tiene por objeto el pleno desarrollo de la persona en las distintas etapas de su vida. (...) Corresponderá al Estado, asimismo, fomentar el desarrollo de la educación en todos sus niveles; estimular la investigación científica y tecnológica, la creación artística y la protección e incremento del patrimonio cultural de la Nación.

25‥- El derecho del autor sobre sus creaciones intelectuales y artísticas de cualquier especie, por el tiempo que señale la ley y que no será inferior al de la vida del titular.

El derecho de autor comprende la propiedad de las obras y otros derechos, como la paternidad, la edición y la integridad de la obra, todo ello en conformidad a la ley.

Se garantiza, también, la propiedad industrial sobre las patentes de invención, marcas comerciales, modelos, procesos tecnológicos u otras creaciones análogas, por el tiempo que establezca la ley.

Será aplicable a la propiedad de las creaciones intelectuales y artísticas y a la propiedad industrial lo prescrito en los incisos segundo, tercero, cuarto y quinto del número anterior.

Asimismo, la nueva normativa constitucional establece para la seguridad de los preceptos constitucionales y el respeto de los mismos por parte del Estado y de los ciudadanos, el recurso de "protección" y el recurso de "amparo", expresados en el Artículo 20 de la Constitución (Navarro, 2012: 630). Sin embargo, estos recursos no 
amparan ni protegen a la totalidad del catálogo de derechos fundamentales, sino principalmente aquellos individuales, quedando fuera de la protección de este recurso los derechos sociales y prestacionales (Nogueira, 2006: 356) expresados en los numerales $\mathrm{N}^{\circ} 9$ (derecho a la protección de la salud), $\mathrm{N}^{\circ} 10$ (derecho a la educación) y $\mathrm{N}^{\circ} 18$ (derecho a la seguridad social). En el caso del derecho de autor y el derecho a la libertad de expresión, la protección (en lo estrictamente normativo) es completa, sin embargo, ni el fomento ni la estimulación a la cual el Estado se obliga por la vía del derecho a la educación cuenta con la posibilidad de utilizar este recurso procesal al momento de verse vulnerado o conculcado.

\section{Incorporación plena del Derecho Internacional Público}

Posteriormente, y ya recuperada la democracia política a nivel institucional a partir de 1990, se inicia el debate en torno a cómo garantizar y/o proteger de mejor manera lo que en los tiempos de la dictadura había sido extremadamente constreñido. El desarrollo artístico sufrió un retroceso notable durante las décadas anteriores, y de la mano de la ratificación de tratados internacionales, el Estado chileno integra de pleno derecho al ordenamiento jurídico instrumentos como el Pacto Internacional de Derechos Económicos, Sociales y Culturales (1989), la Convención Americana sobre Derechos Humanos ("Pacto de San José de Costa Rica", 1991) y el Pacto Internacional de Derechos Civiles y Políticos (1989).

En la materia que nos interesa, el primero de ello establece a toda persona la garantía de participación en la vida cultural común, el goce de los beneficios del progreso científico y sus aplicaciones -mas no el progreso artístico-, y la protección de los intereses morales y patrimoniales que le corresponden en razón de sus producciones artísticas o científicas, además de comprometer a los Estados Parte a respetar: "la indispensable libertad para la investigación científica y para la actividad creadora" (Artículo $\mathrm{N}^{\circ} 15$ ). La Convención Americana a su vez fortalece el derecho a la libertad de pensamiento y expresión, exigiendo que sus limitaciones sean normadas mediante ley y con fundamento estricto en el respeto a los derechos y reputación de los demás, o la protección de la seguridad nacional, el orden público, o la salud y moral pública (Párrafo $2^{\circ}$, Artículo $\mathrm{N}^{\circ} 13$ ), sumando a ello la única forma válida de accionar la censura previa, aquella basada en la "protección moral de la infancia y adolescencia" (Vial, 2006: 251). El Pacto Internacional sobre Derechos Civiles y Políticos no agrega mucho más a lo ya señalado, pero instala su acento en la que ha sido denominada libertad de información, fortaleciendo el derecho a la libertad de expresión, al señalar: "este derecho comprende la libertad de buscar, recibir y difundir informaciones e ideas de toda índole, sin consideración de fronteras, ya sea oralmente, por escrito, o en forma impresa o artística, o por cualquier medio de su elección” (Artículo $\mathrm{N}^{\circ}{ }^{19}$ ). 
De esta frondosa normativa internacional, antecedida por el artículo $27^{\circ}$ de la Declaración Universal de Derechos Humanos de 1948 (que establece el derecho a "gozar de las artes"), se ha ido hilvanando de manera consistente diferentes apreciaciones en torno a la pregunta sobre qué delimita de manera precisa el derecho a la libertad de creación artística. En esto, la Organización de Naciones Unidas junto a la UNESCO han desempeñado una labor encomiable y titánica: buscar definir el concepto "obra de arte" -en permanente disputa-, y cómo ésta puede ser protegida en el campo jurídico internacional, impetrando claridad a una materia de por sí confusa:

La obra de arte se diferencia de las declaraciones que no son ficción en que la gama de significados múltiples que pueden atribuírsele es mucho más amplia; por ello son extremadamente difíciles de demostrar las suposiciones sobre el mensaje transmitido por una obra de arte, y las interpretaciones que se den a esta no tienen por qué coincidir con el significado que se propuso darle el autor. Las expresiones y creaciones artísticas no siempre transmiten un mensaje o una información específicos, y no debe considerarse que los que los hacen son artistas. Además, el recurso de la ficción y lo imaginario debe entenderse y respetarse como un elemento crucial de la libertad indispensable para las actividades creativas $\mathrm{y}$ las expresiones artísticas: las representaciones de lo real no deben confundirse con lo real, (...) los artistas deben poder explorar el lado más oscuro de la humanidad y representar delitos o situaciones que algunos podrían considerar "inmorales" sin ser acusados de promoverlos. ${ }^{4}$

\section{El derecho a la libertad de creación artística}

El avance de la normativa jurídica internacional, la mejora en los estándares democráticos del continente, el desarrollo económico y financiero sostenido a lo largo de gran parte de la década de los noventa y la "normalización democrática" en el caso chileno, permitió que la suerte de "apagón cultural" vivido en dictadura poco a poco fuera perdiendo fuerza, revitalizándose el apoyo estatal a la cultura, el fomento de las artes y el desarrollo de circuitos investigativos de mediana escala. Un punto importante de inicio fue la implementación de diversas leyes para el fomento y desarrollo de la actividad artística, como la Ley $\mathrm{N}^{\circ} 18.838$ que crea el Consejo Nacional de Televisión, la Ley 19.846 sobre Calificación de Producción Cinematográfica, la Ley

${ }_{4}$ Consejo de Derechos Humanos de Naciones Unidas, 2013. Informe de la Relatora Especial sobre los derechos culturales, Farida Shadeed, "El Derecho a la libertad de expresión y creación artística". Párrafo 37. 
$\mathrm{N}^{\circ} 19.227$ que crea el Fondo Nacional de Fomento al Libro y la Lectura o la Ley $\mathrm{N}^{\circ} 18.985$ sobre Donaciones con Fines Culturales, entre otros cuerpos normativos. Avance que tuvo su punto cúlmine con el mensaje presidencial del 14 de abril de 1997 sobre el proyecto de reforma constitucional para introducir una disposición exclusiva destinada al establecimiento del derecho a la libertad de creación y difusión de las artes. Esta reforma busca explicitar la mayor protección requerida por la actividad creadora para diferenciarse del derecho a la libertad de expresión y, por consiguiente, del derecho a la libertad de opinión e información por entonces contenidos en el numeral $12^{\circ}$ del catálogo de derechos fundamentales (Vial, 2006: 260).

Dentro del largo debate suscitado, los puntos más controversiales eran si acaso el nuevo derecho debía ser establecido de manera autónoma (esto es, con un artículo propio) o bien si debía ser anexado dentro de los incisos correspondientes al derecho a la libertad de expresión o al derecho de autor. Además, existían divergencias sobre si acaso debía plegarse el ejercicio de esta libertad al ámbito de las ciencias, pues claramente eran ellas también producto de la creación intelectual humana. Empero, el debate parlamentario concluyó sin acuerdo respecto a las ciencias, y en palabras del senador Parra, "perdiéndose una preciosa oportunidad para que la consagración constitucional de la libertad de investigación científica hubiese quedado también plasmada"; y se determinó el traslado del derecho propuesto desde el Artículo 19 $\mathrm{N}^{\circ} 12$ (que establece la libertad de expresión) al Artículo 19 №25 (que establece el derecho de autor), con motivo de evitar las implicaciones penales que traía el establecimiento de este derecho en el anterior numeral. Así finalmente, el 8 de agosto del año 2001, sería aprobada la reforma constitucional contenida en la ley 19.7425 , y promulgada el día 25 del mismo mes, quedando en su redacción final de la siguiente manera:

Artículo 19. La Constitución asegura a todas las personas:

25‥- La libertad de crear y difundir las artes, así como el derecho del autor sobre sus creaciones intelectuales y artísticas de cualquier especie, por el tiempo que señale la ley y que no será inferior al de la vida del titular.

En línea con la reglamentación anterior, los demás incisos del numeral 25 no sufrieron modificación alguna y se mantienen hasta hoy redactados de igual manera a como fueron promulgados en 1980 .

\footnotetext{
5 Boletín №2016-07-1. Informe de la Comisión de Constitución, Legislación y Justicia sobre el proyecto de reforma constitucional que consagra el derecho a la libre creación artística y elimina la censura cinematográfica, sustituyéndola por un sistema de calificación.
} 


\section{Controversias actuales y futuras}

Puede observarse como encomiable toda acción legislativa destinada a añadir un nuevo derecho al catálogo de derechos fundamentales. Puede aplaudirse, y no sin razón, el cambio de jerarquía jurídica desde un simple precepto legal a un precepto constitucional. Sin embargo, lo que en un principio nos parece meritorio, noble y elevado, con el paso del tiempo puede marchitarse de manera irreversible, pues al chocar la abstracta norma con la exigente realidad, se cae su máscara y se revela como ineficaz, o peor aún, inútil.

Por ejemplo, en cuanto a la justicia constitucional, y sobre todo aquella surgida con posterioridad a la reforma constitucional del año 2005 que entrega nuevas atribuciones y facultades al Tribunal Constitucional, no ha existido discusión en la justicia constitucional respecto a los alcances, elementos, o bien "la esencia" del "derecho a la libertad de creación artística". El único caso (STC 1144) donde se discute la naturaleza y alcance del numeral 25 , reside su controversia en el derecho de autor relativo a la obra literaria en litis. Por tanto, puede establecerse razonadamente que a pesar de encumbrar en la propia Constitución la actividad creadora, luego de aproximados veinte años desde su existencia, sabemos que no ha sido controvertida. Lo que nos lleva a inferir que nos encontramos frente a una normativa de carácter meramente simbólico:

Si miramos el contexto, el numeral y las palabras que se utilizan para la incorporación de este nuevo precepto, más que una nueva libertad estamos simplemente ante la presencia de una especificación de lo que ocurre con la propiedad de las creaciones artísticas, cuestión que se explica, en parte, por la obsesión de nuestro constituyente ("originario" y "derivado") con el derecho de propiedad (Lovera, 2010: 162).

En el tiempo reciente, muchos han sido los casos judiciales en los que obras artísticas de cualquier tipo han buscado ser censuradas, objetadas, canceladas o limitadas en su desenvolvimiento mediato o inmediato tanto por la autoridad pública como por otros particulares que han visto en estas obras una cierta amenaza a sus creencias, honra o patrimonio. De igual modo, con motivo de las manifestaciones masivas y populares acaecidas con posterioridad a la ocurrencia del estallido social de octubre del año 2019, fue la propia policía la que dispersaba y obstaculizaba las diferentes expresiones artísticas ocurridas en el espacio público en la forma de bailes o coreografías masivas, desfiles ciudadanos, performances, obras lumínicas de proyección colosal y espectáculos masivos, como lo fue el caso de Plaza Italia, denominada coloquialmente "Plaza Dignidad", en esta nueva resignificación como escenario de expresión política y cultural (Gana, 2021: 79). El hecho de que ninguna 
de estas vulneraciones a la libertad de creación artística -ya que algunas expresiones artísticas en sus acepciones contemporáneas se realizan al mismo tiempo de su ideación-, terminara en un litigio de carácter judicial o judicial-constitucional, no es sino demostrativo de la falta de eficacia del derecho en la realidad. Incapaz de defender debidamente a las propias expresiones artísticas, podemos decir que nos encontramos frente a un derecho falto de contenido sustancial en su aplicación; pues también -agregamos aquí-, la totalidad de los litigios judiciales antes existentes, al menos desde la "normalización democrática", se han resuelto por la vía del "derecho a la libertad de expresión", no siendo entonces controvertido, ni discutido, ni aclarado, ni especificado, el objeto preciso de protección al momento de aludirse a la "libertad de creación artística" como tal, evidenciando su insuficiencia:

(...) reconocer a la libertad de creación artística el carácter de derecho fundamental autónomo, con particularidades propias respecto de la genérica libertad de expresión, es preciso que, por un lado, pueda dibujarse al menos una cierta noción de lo que haya de entenderse por creación artística, que la distinga de otras formas de expresión y, por otro lado, que a esa noción esté asociado un régimen de tratamiento jurídico propio (Ruiz, 2021: 137).

En esto observamos una cierta confusión en el derecho contemporáneo, el cual busca con extasiada ambición la incorporación, declaración y reglamentación de más y más derechos fundamentales, sin tomar en consideración que lo que realiza finalmente, es la expansión de los ya "clásicos" derechos. El mismo concepto de "la libertad de...", como cualidad del comportamiento humano (Pereira, 1998: 415), puede ser multiplicado la cantidad de veces que se desee para el ejercicio, facultad o acto que busca protegerse, pero aquello no significa que se entregue efectiva garantía y protección jurídica. Por lo demás, la resolución de un conflicto contencioso constitucional, suele ser juzgado en la generalidad de las ocasiones mediante un ejercicio de ponderación entre los mismos derechos. Ponderaciones establecidas en distinto grado; sin embargo, ¿cómo ponderar entre dos derechos que, siendo uno definido de manera total y el otro de manera incompleta, presentan igual rango?

Si cabe hacer algún reproche a una postura teórica o doctrinaria, en general, y este es el caso respecto a la ponderación, es el tener por efecto el bloquear la discusión científica sobre los correspondientes tópicos. Al presentarse como la vía de redención frente a una subsunción incapaz de dar cuenta de las necesidades de la interpretación y aplicación de principios constitucionales, el método de ponderación reduce todo el campo del debate a una sencilla línea entre dos puntos que, plantados 
como únicas alternativas extremas -subsumir o no subsumir-, se tornan banales (Aldunate, 2010: 98).

Una manera de explicar la confusa problemática sobre la ponderación de derechos constitucionales, su ámbito de protección y su definición como derecho autónomo es la que se puede dar con ocasión de digital surrogates, denominación utilizada para aquellas digitalizaciones de obras de arte que permite trasladar al medio digital un soporte físico. Estas son realizadas muchas veces por instituciones culturales que tienen por objeto preservar la imagen de una obra que evidentemente será dañada por el tiempo o las circunstancias; y sobre las cuales estas instituciones pueden alegar para sí un derecho de propiedad intelectual, inhibiendo potencialmente a la posterioridad la posibilidad de creación artística con obras que pertenecen al patrimonio cultural común, como lo podría ser en el caso de la conformación de un collage o un fotomontaje. Situación que puede ser descartada al ser Latinoamérica un espacio en el cual sobre materias de infraestructura de metadatos todavía existe una potencialidad en desarrollo (Pabón, 2019: 70).

En consecuencia, lo que en un principio podría pertenecer a una cuestión relativa a los derechos de propiedad intelectual vinculados al Copyright -derecho a copia que implica la reserva de todos los derechos, sean éstos de cualquier índole (discusión en el ámbito anglosajón al menos desde el siglo XVIII y que en el ámbito continental se resuelve por la vía de los denominados derechos morales)-, a las licencias de Creative Commons -que pueden traducirse bajo la fórmula: "algunos derechos reservados", estableciendo para ello tramos de otorgamiento de licencias de distinto tipo-; o el Copyleft -que busca impedir el aumento de productos vinculados al copyright proponiendo una licencia pública general (Jiménez, 2007: 72)-, se convierte en una nueva problemática de carácter constitucional pues se afectaría directamente el derecho a gozar de las artes y el derecho a la libertad de creación artística. Generando un problema de escasez donde antes no lo había a causa de una legislación que debería propiciar precisamente lo contrario (Benegas Lynch, 1999: 321).

\section{Conclusión}

Realizada esta síntesis de lo que ha sido la evolución del derecho a la libertad de creación artística desde los antecedentes de la tradición constitucional chilena hasta la actualidad, podemos señalar con claridad que este derecho se encuentra en constante evolución, y que aún es necesaria la controversia para delimitar de mejor manera su esencia, composición y alcance.

El futuro debate constitucional deberá al menos manifestarse de forma clara respecto a una mayor protección a las obras artísticas y de sus ejecutores y creadores. La experiencia reciente ha demostrado que falta aún una concepción integral en torno 
a la cultura y el cuidado que nos merece ella. Los olvidos y negligencias en este ámbito son frecuentes, e incluso han sido mayores que aquellos que han afectado al entorno natural y silvestre de nuestro país. Todo es avance en un terreno ausente de exploración y ávido de descubrimientos.

No obstante, puede establecerse que nos encontramos frente a una primera disyuntiva, pues desarrollada durante dos siglos una acentuada preminencia del derecho de propiedad en la legislación nacional, llevada hasta el paroxismo en la actual Constitución, la realidad digital presenta enormes desafíos pues ésta permite la multiplicidad de soportes y, por ende, la capacidad de reproducir una misma obra sobre diferentes bienes hasta el infinito. Habrá en un futuro permanente conflicto sobre si la prevalencia de los derechos patrimoniales debiese mantenerse en desmedro de los derechos morales que nos suscitan a todos cuando se trata de obras artísticas pertenecientes al patrimonio cultural común. Y es precisamente la actual Convención Constitucional la llamada a resolver esta disyuntiva, al contar con la legitimidad para ello.

Los nuevos métodos de inventiva, el avance de la sociedad cada vez más tecnologizada, las distintas ideologías sobre las cuales se cimenta la acción del Estado o la propia caracterización de éste han confluido en un movimiento dinámico al momento de establecer derechos o garantías tanto a los autores como a las obras artísticas. Sin tener nunca un punto fijo, el arte, vanguardia de expresión social, exige y solicita siempre mayores desafíos al derecho, pues ya no solo se requiere de su permisividad, sino que también de la no intervención de terceros, su cuidado en la forma de patrimonio, su resguardo y almacenamiento legítimo, su comercialización segura y su integridad a pesar de los embates del tiempo y de las épocas. Arte y Derecho son los rostros más acrisolados de la civilización humana, los más duraderos, los eternos y perennes. Los faroles en épocas de crisis, los motores en tiempos de implosión y explosión. Son, en definitiva, las dos caras de una misma moneda: la persona humana.

\section{Bibliografía}

Aldunate, E. (2010): "Aproximación conceptual y crítica al neoconstitucionalismo", Revista de Derecho, 23(1), 79-102.

Anadón, J. (2005): Historiografía Literaria Latinoamericana Colonial-Contemporánea (1973-1993). Ciudad de México, Universidad de Notre Dame, Seminario de Cultura Mexicana. 
Andrade, C. (1963): Elementos del Derecho Constitucional Chileno. Santiago, Editorial Jurídica de Chile.

Bravo, B. (2016): Una historia jamás contada. Chile 1811-2011. Santiago, Origo.

Benegas, A. (1999): “Apuntes sobre el concepto de Copyright”, Estudios Públicos, 75, 317-341.

Cerda, A. (2015): "Evolución histórica del derecho de autor en América Latina", Ius et Praxis, 22(1), 19-58.

Concha Monardes, R. (2016): El Reino de Chile, realidades estratégicas, sistemas militares y ocupación de territorio (1520-1650). Santiago, Editorial CESOC.

Correa, S., Ruiz Tagle, P. (2010): Ciudadanos en democracia. Fundamentos del sistema político chileno. Santiago, Debate.

Cristi, R. (1993): "La noción del poder constituyente en Carl Schmitt y la génesis de la Constitución chilena de 1980", Revista Chilena de Derecho, 20, 229-250.

Daistman, A. (1998): "Diálogos entre artesanos. Republicanismos y liberalismos populares en el Chile decimonónico", Revista Universum, 13, 83-105.

Dunn, J. (2014): Libertad para el pueblo. Historia de la democracia. Ciudad de México, Fondo de Cultura Económica.

Encina, F.A. (1956): "La América Española hacia 1810", Anales de la Universidad de Chile, 114 (103), 9-37.

Escobar, G. (1998): "Derechos Fundamentales: una aproximación general", Anuario de la Facultad de Derecho de la Universidad de Alcalá de Henares, 8, 127-156.

Ferguson, N. (2005): El Imperio Británico. Cómo Gran Bretaña forjó el orden mundial. Madrid, Debate.

Figueroa, M. A. (1967): "Apuntes sobre el origen de las garantías a los derechos humanos en la legislación hispano-chilena", Revista de Historia de las instituciones políticas y sociales, 2, 33-73.

Gana, A. (2021): "Estructuración del espacio público entre política y fiesta: el caso de Plaza Italia en Santiago, Chile", Revista de Urbanismo, (44), 76-95. 
Hauser, A. (2012): Historia social de la literatura y el arte. Tomo Segundo. Barcelona, Editorial de Bolsillo.

Infante, J. (2019): "Proteger lo original: Consideraciones en torno durante la primera etapa de la legislación patria", Revista Chilena de Derecho, 46(1), 253-278.

Jiménez, A. (2007): "Copyleft y creative commons: una alternativa para la libre difusión del conocimiento", Innovación Educativa, 7(39), 70-77.

Lovera, D. (2010): "El mito de la libertad de expresión en la creación Artística”, Revista de Derecho, 23(1), 156-179.

Martínez Dalmau, R. (2014): “Arte, derecho y derecho al arte”, Revista Derecho del Estado, 32, 35-56.

Navarro, E. (2012): "35 años del recurso de protección, notas sobre su alcance y regulación normativa”, Estudios Constitucionales, 10(2), 617-642.

Nogueira, H. (2006): “La evolución político constitucional de Chile 1976-2005”, en Nogueira Alcalá, H. Coord., La evolución político constitucional de América del Sur (1976-2005). Santiago, Librotecnia, 337-398.

Pabón, J. (2020): "Protección legal a los metadatos y gestión digital del autor", Revista Ius et Praxis, 26(1), 57-76.

Pereira, A. (1998): Teoría Constitucional. Santiago, Editorial Jurídica Conosur.

Prieto, A. (2013): Visión íntegra de América. América: conformación colonialista. Tomo I. La Habana, Ocean Sur.

Razuváev, V. (1989) Bernardo O’Higgins. Conspirador, General, Estadista. Moscú, Progreso.

Ruiz, N. (2021): "La libertad de creación artística, ¿un derecho autónomo? (L’oiseau rebelle en la Constitución y en la jurisprudencia constitucional)", Revista de Administración Pública, 215, 111-142.

Stolley, K. (2006): "Formas narrativas, erudición y saber", en Roberto González Echevarría, Enrique Pupo-Walker ed., Historia de la literatura hispanoamericana, Tomo I, Del Descubrimiento al Modernismo. Ciudad de México, Gredos, 354-390. 
Subercaseaux, B. (2000): Historia del Libro en Chile (Alma y cuerpo). Santiago, LOM Ediciones.

Trujillo, S. (2019): Andrés Bello. Libertad, Imperio y Estilo. Santiago, Editorial Roneo.

Vial, T. (2006): “El derecho a la libertad de creación artística en la Constitución”, en F. González (ed.), La libertad de expresión en Chile. Santiago, Universidad Diego Portales, 243-284.

Fecha de recepción: 12 de agosto de 2021

Fecha de aceptación: 18 de enero de 2022 